\author{
Military Technical College \\ Kobry El-Kobbah, \\ Cairo, Egypt.
}

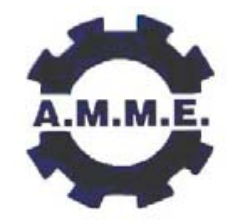
$13^{\text {th }}$ International Conference on Applied Mechanics and Mechanical Engineering.

\title{
FATIGUE CRACK GROWTH OF STAINLESS STEEL FIBER REINFORCED ALUMINUM COMPOSITES
}

\author{
ESKIZEYBEK V.., AVCI A. ${ }^{* *}$, ATABERK N. ${ }^{\star * *}$ and YAPICI A.
}

\begin{abstract}
In this study, fracture behavior of stainless steel/aluminum laminated composites with middle through thickness crack under fatigue loading, was investigated. The composite material, which has unidirectional continuous AISI 304 stainless steel as fibers and Al 2024 as matrix, was produced by using diffusion bonding. The fatigue tests were conducted under agreement with the ASTM E647 standard. The crack initiation, damage behavior, fatigue crack-growth rate $(d a / d N)$, stress intensity factor $(\Delta K)$, strain energy release rate $(\Delta G)$ and fracture toughness $\left(K_{I C}\right)$ were determined. Moreover, $\Delta G$ value was obtained by using Linear Elastic Fracture Mechanics (LEFM) and compliance methods and the results were compared with each other. Also, $d a / d N-\Delta K$ and $d a / d N-$ $\Delta G$ were plotted for determining fracture behavior under fatigue loading of the composite material.
\end{abstract}

\section{KEY WORDS}

Fatigue, through thickness crack, aluminum matrix composites, compliance method.

Research Assistant, Dpt. of Mechanical Eng., Selcuk University, Konya, Turkey

** Professor, Dpt. of Mechanical Eng., Selcuk University, Konya, Turkey.

*** Assistant professor, Kadinhani Faik Icil Vocational School, Selcuk University, Konya, Turkey.

**** Assistant professor, Dpt. of Mechanical Eng., Selcuk University, Konya, Turkey. 


\section{INTRODUCTION}

Fibre Reinforced Metal Laminates (FRMLs) have superior performance at elevated temperatures compared to glass-reinforced plastics. The strength and elastic moduli of metal matrices are higher than those of resin matrices over a wide range of temperature. The stress concentrations educed by cracked fibers can be relaxed through the plastic deformation of matrix. As a result, there is a less chance of a brittle failure of the composite materials [1].

FRMLs developed for improving the resistance of aluminum alloys to fatigue crack growth, are fabricated by bonding thin metallic sheets with fiber reinforced adhesive matrix. Among the types of FRMLs, Al-based continuous fiber reinforced composites find wide usage in areas like aerospace, space and automobile sectors. These composites exhibit exceptional specific strength and stiffness in the longitudinal direction and it has been shown that the experimental elastic modulus can approach theoretical ROM (Ratio of Mixture) value when loaded in the direction of fiber orientation [2-3]. The fatigue performance of fibre reinforced metals has been extensively investigated; many theoretical and experimental results are reported in the literatures, which account for surface cracks, fracture mechanics parameters, effect of notches, the strain energy density, the loss of stiffness, stress ratios, elasto-plastic solutions, etc. Devranjish [4] developed a new fatigue crack growth model for fiber reinforced polymer matrices. The proposed model takes into account the progressive damage that occurs at each load increment in fatigue cycling through a weighted average stress intensity factor. Besides, the effect of notch conditions on the fatigue of a glass-fiber reinforced polypropylene composites were investigated by Ferreira et al. [5]. They also studied the analysis of fatigue and damage in glass-fiber reinforced polypropylene composite materials [6]. They reported some important results about damage mechanism, effects of temperature, stress ratio, notch and fracture mechanisms. Nalla et al. [7] investigated mixed mode high cycle fatigue crack growth in metal matrix composite, and especially reported the effect of small cracks. Newman and Haines [8] examined the role of specimen type used in the ASTM Standard Test Method for Measurement of Fatigue Crack Growth Rates (E-647). They used two different $M(T)$ specimen type and questioned the influence of specimen height specified in the standard. Besides, Bi-linear log-log model was applied to stress amplitude versus fatigue life data of 14 aluminum alloys by Fatemi et al. [9]. They reported that the bi-linear $S-N$ model provides a much better representation of the data than the commonly used linear model for Al alloys. Moiser et al. [10] investigated fiber reinforced aluminum composites under fatigue loading. Their experimental results exhibit gradual fibers fracture during fatigue loading, with the number of fiber breaks increasing linearly with the logarithmic cycle number. Wang et al. [11] examined very long life fatigue fracture behavior of 7075 and $6061 \mathrm{Al}$ alloys in T6 condition and observed that fatigue failure in Al alloys ascribed to the formation of a number of fatigue voids, their growth and coalescence and the subsequent formation and propagation of macroscopic cracks. Mixed mode fatigue crack growth behavior in an aluminium alloy was analysed by Borrego et al. [12]. Jeong [13] used two different fracture criteria to determine the crack trajectory or angle of crack propagation in 2024-T3 aluminum alloy under mixed mode conditions. Avci et al. [14] determined stress intensity factors by using compliance and $\mathrm{J}$ integral methods in steel fiber reinforced concrete composites. Erkendirci et al. [15] investigated the fatigue and fracture behavior of woven steel reinforced high density polyethylene (HDPE) thermoplastic composite having a middle 
tension (MT) specimen with through-thickness crack. They found strain energy release rate values for composite material by using LEFM and Compliance Method.

\section{EXPERIMENTAL PROCEDURE}

\section{Specimen Preparation}

For the production of the sandwich composite material to be considered in this investigation commercial Al 2024 aluminum alloy as a matrix and AISI 304 stainless steel fibers were used. Two aluminum sheets, each of them has $3 \mathrm{~mm}$ thickness and 35 $\mathrm{mm}$ width, were prepared as a plate Stainless steel fibers, of diameter $0.7 \mathrm{~mm}$ and length of specimen, were prepared.. The fibers were put between two aluminium plates as in shown Fig. 1. This composite sandwich was placed in a mold at room temperature. Mold was heated to $585 \quad C$ and when mold and sandwich reached to this temperature, mold was pressed under $0.3 \mathrm{MPa}$ for $45 \mathrm{~min}$. Thus aluminum-stainless steel laminated composite was manufactured. This method is named diffusion bonding method [1]. If pressing time is long enough, matrix can be integrated with fibers well. After pressing, the composite material was cut $200 \mathrm{~mm}$ length and $25 \mathrm{~mm}$ width for fatigue tests. The thickness of composite material is $3 \mathrm{~mm}$ with a fiber volume fraction $\left(V_{f}=0.1\right)$.

\section{Tensile Test}

Tensile tests were performed in order to determine the mechanical properties of the composite material. The specimens were prepared according to ASTM E 399, as shown in Fig. 2. The tests were carried out on Lloyd Instruments T50 K Tensile Testing Machine and load was applied at rate of $0.5 \mathrm{~mm} / \mathrm{min}$. The modulus in the direction of the fibers $E_{1}$ and the Poisson's ratio $v_{12}$ were characterized by means of tension tests on unidirectional coupons that are instrumented with two electric resistance strain gages, which one in the fiber direction and the other perpendicular to it. The specimen was loaded in gradually up to rupture. $E_{1}$ and $v_{12}$ values were obtained experimentally. $\mathrm{G}_{12}$ was calculated by using the values of $\mathrm{E}_{1}$ and $v_{12}$. Furthermore; the specimen but with the fibers oriented perpendicular to the direction of the applied load was loaded in the same conditions to obtain modulus of elasticity $\left(E_{2}\right)$. Poisson's ratio $v_{21}$ was calculated theoretically according to following expression:

$v_{21}=v_{12} E_{2} / E_{1}$

\section{Fatigue Test}

The geometry and dimensions of the fatigue test specimens were prepared according to the ASTM E-647 [16], as shown in Fig. 3. For middle tension $M(T)$ specimen, it is recommended [17] that thickness of the specimen $(B)$ must be within the range of $(W / 8 \leq B \leq W / 4)$. Also for the $M(T)$ specimen the following is required:

$(W-2 a) \geq 1.25 P_{\max } /\left(B \sigma_{y s}\right)$ 
where $a$ is the crack length, $W$ is width of specimen and $\sigma_{y s}$ is yield strength of material determined at room temperature as used when measuring the fatigue crack growth rate data [16].

Fatigue tests were carried out in Universal Testometric Micro 500 electro-mechanical machine at constant frequency and stress ratio. The load was controlled by a load cell, so that the load wave was sinusoidal at constant amplitude. All the tests were performed in tension to tension fatigue test $\left(P_{\min }=200 \mathrm{~N}\right.$ and $\left.P_{\text {max }}=2000 \mathrm{~N}\right)$ with load ratio of $R=0.1$ and frequency of $0.65 \mathrm{~Hz}$ at room temperature. During the tests, the crack growth rate was measured for every 250 cycles by visual inspection captured through a Mitutoyo hand visual microscope with $0.1 \mathrm{~mm}$ scale. Moreover, at every 250 cycles, shape of the crack was recorded on a digital camera for controlling the measured values of the crack growth. Then stress intensity factor was calculated as follows [17]:

$$
\begin{aligned}
& \Delta K=\frac{\Delta P}{B} \sqrt{\frac{\pi \alpha}{2 W} \sec \frac{\pi \alpha}{2}} \\
& \Delta P=P_{\text {max }}-P_{\text {min }} \quad R>0, \quad \alpha=2 a / W, \quad 2 a / W<0.95,
\end{aligned}
$$

where $R$ is the load ratio, $a$ is the crack length, $W$ is width of specimen, $B$ is the thickness of specimen and $\Delta P$ is load range. Strain energy release rates $(\Delta G)$ were calculated by LEFM and compliance methods for crack propagation in a plane of elastic symmetry such as the plane normal to the fiber direction for orthotropic materials [17]. The formulations for $\Delta G$ were given in equations (4) and (6).

$\Delta G=\Delta K^{2}\left\{\left(\left(a_{22} a_{11}\right) / 2\right)^{1 / 2}\left[\left(a_{22} / a_{11}\right)^{1 / 2}+\left(\left(a_{66}+2 a_{21}\right) / 2 a_{22}\right)\right]^{1 / 2}\right\}$,

where $a_{11}=1 / E_{1}, a_{22}=1 / E_{2}, a_{21}=a_{12}=-v_{12} / E_{1}=-v_{21} / E_{2}, a_{66}=1 / G_{12}$

In the equation (4), $E_{1}$ and $E_{2}$ are moduli of elasticity for $x$ and $y$ direction, respectively, $v_{12}$ and $v_{21}$ are Poisson ratios for $x y$ and $y x$ planes, respectively, $G_{12}$ is shear modulus for $x y$ plane. The crack growth or the crack extension is defined as the compliance, which is the ratio of the crack opening displacement to applied load, as given by Eqn. (4) [Ref. 4].

$C=\frac{C O D}{P}$,

where $C O D$ is the crack opening displacement, $P$ is the applied load and $C$ is the compliance. For the compliance method, $\Delta G$ is calculated by the following equation:

$\Delta G=\frac{P^{2}}{2 W} \frac{d C}{d a}$. 


\section{RESULTS AND DISCUSSION}

\section{Tensile Test}

The mechanical properties of the composite material, obtained from tensile tests, are given in Table 1.

\section{Fatigue Test}

The specimens were initially given pre-crack growth under fatigue loading and the fatigue pre-crack growth was observed at $\Delta a=0.1 \mathrm{~mm}$ and $N=490$ cycles. After precracking the fatigue tests were carried out. During the fatigue test, the magnitude of the crack growth was measured in terms of corresponding fatigue cycles. Fig. 4 illustrates the fatigue crack growth versus number of cycles; the magnitude of the crack growth increases with the fatigue cycles.

As shown in Fig. 4, the variation of crack growth with the number of cycles is almost linear up to 1510 cycles. However, beyond that point a sudden increase was observed. Specimen was fractured (as shown in Fig. 4) at about 2050 cycles and $5.5 \mathrm{~mm}$ crack length.

\section{Fracture Behavior}

The modes of failure which are generally caused due to presence of cracks are fracture and fatigue. Under fatigue loading of materials, existence of crack and hence crack growth significantly affects the performance and life of the part. Fracture mechanics analyses are very helpful in predicting the effects of the crack on basic fatigue behavior. In this study, one failure mode (mode $I$ ) was observed for the $M(T)$ specimen with through-thickness crack during the fatigue test. So, only values of the stress intensity factor range $\left(\Delta K_{I}\right)$ and the strain energy release rate $(\Delta G)$ were examined.

Figure 5 shows the variation of crack growth rate $(d a / d N)$ with the stress intensity factor $(\Delta K)$ range on a logarithmic scale. In Fig. 5, $\Delta K_{I}$ and $d a / d N$ are seen to increase linearly at the stable region. Then increments of $\Delta K_{I}$ and $d a / d N$ became nonlinear at the unstable region and failure occurred. Initially, $\Delta K$ was $94.87 \mathrm{MPa} \sqrt{\mathrm{mm}}$ at $a=5.13$ $\mathrm{mm}, \mathrm{N}=490$ cycles, then $\Delta K$ became $137.23 \mathrm{MPa} \sqrt{\mathrm{mm}}$ at $\mathrm{a}=10.5 \mathrm{~mm}, \mathrm{~N}=2050$ cycles before failure.

Figure 6 shows the variation of crack growth rates $(d a / d N)$ with strain energy release rate $(\Delta G)$ range on a logarithmic scale. There are many similarities between Fig. 6 and Fig. 5 as expected. So, $\Delta G$ and $d a / d N$ are seen to increase linearly at the stable region. Then increments of $\Delta G$ and $d a / d N$ became nonlinear at unstable region and failure was occurred. Initially $\Delta G$ was $22.5 \mathrm{~J} / \mathrm{mm}^{2}$ at $a=5.13 \mathrm{~mm}$ at $N=490$ cycles, then $\Delta G$ became $47 \mathrm{~J} / \mathrm{mm}^{2}$ at $a=10.5 \mathrm{~mm}$ at $\mathrm{N}=2050$ cycles before failure.

\section{Investigation of $\Delta \mathbf{G}$ Using Compliance Method}

Compliance method is an alternative method for determination of $\Delta G$. The determination of the compliance has been used to estimate the crack length in metals, 
polymers as well as composites [4]. During the fatigue test, the Crack Opening Displacement $(C O D)$ is measured using a Mitutoyo hand visual microscope with 0.1 $\mathrm{mm}$ scale under maximum $(2000 \mathrm{~N})$ and minimum $(200 \mathrm{~N})$ fatigue loads at the crack mouth. As the fatigue damage grows in either size, intensity or both, the compliance increases. From the values of $C O D$ and load, the compliance is calculated at regular intervals of fatigue damage growth and an equivalent fatigue crack length is estimated using the compliance-crack growth relationship obtained from equation (5). P-COD curves were plotted as shown in Fig. 7. In this Figure, increment in $C O D$ values was observed. At the beginning of the test after precracking at $\mathrm{N}=490$ cycles when maximum loading occurred the $\triangle C O D=0,27 \mathrm{~mm}$ and at minimum loading situation $\triangle C O D=0,22 \mathrm{~mm}$ values are measured. Before fracture of composite material $2.078 \mathrm{~mm}$ and $1.593 \mathrm{~mm}$ values were measured, respectively.

Compliance-crack growth $(C / a)$ curve of composite material was plotted as shown in Fig. 8. Then $d C / d a$ was calculated from this curve. The strain energy release rate $(\Delta G)$ was also calculated from equation (6). Thus, these $\Delta G$ values were found with the compliance method and compare to $\Delta G$ values which are obtained from LEFM. Fig. 9 shows $d a / d N-\Delta G$ curves of composite material obtained from LEFM and compliance method.

According to LEFM, $\Delta G$ values were calculated as $22.5 \mathrm{~J} / \mathrm{mm}^{2}$ and $47 \mathrm{~J} / \mathrm{mm}^{2}$ initially and before fracture. Also, according to the compliance method, $\Delta G$ values were found as $22.1 \mathrm{~J} / \mathrm{mm}^{2}$ and $30.1 \mathrm{~J} / \mathrm{mm}^{2}$ initially and before fracture. Thus, there was a difference of $1.5 \%$ between $\Delta G$ values obtained from LEFM and Compliance Method initially. But this difference became $35.9 \%$ before fracture. The reason of disharmony between the two methods could be the plastic behavior of crack tip and energy absorption at the plastic zone. This situation causes to blunt of the crack tip. This energy absorption is not taken into account in LEFM, so LEFM gives more accurate results for brittles materials. The comparison between two methods is important to understand the effect of plastic behavior of crack tip on $\Delta G$ values and there are comparisons like this in literature [15].

\section{Damage Behavior}

In this section the damage mechanism of composite material was investigated. After fatigue precracking the fatigue crack propagated in stable form along the plastic zone at the crack-front (Fig. 10). On the other hand, the crack mouth opening continued until crack reached fiber, where the crack growth rate decreased. The fatigue crack propagated without fiber breakage and at this time necking occurred at the edge of specimen. When crack length reached $a=10.5 \mathrm{~mm}$ all fibers broke in a short time and unstable crack growth was observed. The fracture surface indicates interfacial debonding with fiber pullout (Fig. 11).

In view of these observations the crack growth mechanism of fiber reinforced $M M C s$ can be explained by shear stress concentrations phenomenon at intact fibers [18]. It is well-known that matrix yielding plays a role in the blunting of the crack tip. Another event which causes blunting is splitting that results from longitudinal cracking of the matrix or debonding at the fiber-matrix interface. When cracked unidirectional MMCs are pulled under tension, the crack causes tensile stress and shear stress concentrations between cut and intact fibers. With this concession and up to the 
observations, the stress concentration of the crack tip reached matrix yield strength first and matrix yielding occurred. With increasing stress at the plastic zone, debonding occurred when applied stress was equal to interfacial bonding stress. As a result, the fatigue crack growth without fiber breakage and so fibre bridging was observed. These mechanisms increased the crack growth resistance of the specimen.

\section{CONCLUSION}

In this study, fracture behavior of stainless steel/aluminum laminated composites with middle through thickness crack which is perpendicular to the direction of applied load under fatigue loading, was investigated. First of all, the mechanical properties of the composite material was determined and then the middle trough thickness cracked specimens were prepared. The fatigue tests were performed under conditions $f=0.65$ $\mathrm{Hz}$ frequency and the load ratio $\mathrm{R}=0.1$ according toASTM E 647 standarts. In these tests, following conclusions were dranw:

- Crack growth and fatigue cycle $(a / N)$ curve increased up to 1500 cycles. After this cycle, an unstable crack growth occured and it was the start of unstable crack growth region. Then, the specimens failured in about 2000 cycles.

- In $\mathrm{da} / \mathrm{d} N-\Delta K$, both values (ratio of crack growth rate $\mathrm{da} / \mathrm{d} N$ and stress intensity factor ranges $\Delta K$ ) increased up to fracture. Linear increments occurred at da/d $N$ and $\Delta K$ values in stable crack growth region. But in unstable crack growth region, increments at da/d $N$ values decreased unlinearly.

- In $\mathrm{da} / \mathrm{dN}-\Delta \mathrm{G}$, both values (ratio of crack growth rate da/dN and strain energy release rates $\Delta G$ ) increased up to fracture. Linear increments occurred at da/dN and $\Delta \mathrm{K}$ values in stable crack growth region. But in unstable crack growth region, increments at da/dN values decreased unlinearly.

- While damage starts, formation of plastic zone was observed at crack tips firstly. In addition to this, the thickness of matrix was decreasing in crack growth direction. Necking occured cause of longtional deformation before fracture.

\section{REFERENCES}

[1] Ataberk, N., Uyaner, M., Avcı, A., Koçak, S., Elasto-plastic Stress Analysis of Aluminum Metal-Matrix Composite Plate Under In-plane Loading, J. of Reinforced Plastics and Composites,No 23, pp 563-570, (2004).

[2] Cady, C.M. and Gray, G.T, Influence of Strain Rate on the Deformation and Fracture Response of a 6061-T6 Al-50 vol. $\% \mathrm{Al}_{2} \mathrm{O}_{3}$ Continuous-Reinforced Composite, Mater. Sci. Eng., No A298, pp 52-62, (2001).

[3] Rohatgi, P.K.; Ray, S.; Asthana, R.; Narendranath, C.S., Interfaces in Cast Metal-Matrix Composites, Defence Sci. J. 43, No A162, p 163-174 (1993).

[4] Devrajsinh, R. A., Development of a New Fatigue Damage Growth Model for Polymer Matrix Composites, Doctor of Philosophy, Wayne State University, Detroit Michigan, (1997).

[5] Ferreira J., Costa, J., Richardson, M., Effect of Notch Conditions on the Fatigue of a Glass-Fiber Reinforced Polypropylene Composite, Composites Science 
And Technology, No 57, pp 1243-1248, (1997).

[6] Ferreira J., Costa, J., Reis, P., Richardson, M., Analysis of Fatigue and Damage in Glass-Fiber Reinforced Polypropylene Composite Materials, Composites Science And Technology, No 59, pp 1461-1467, (1999).

[7] Nalla, R.K., Campell, J.P., Rtchie, R.O., Mixed-Mode High Cycle Fatigue Crack Growth Thresholds in Ti-6Al-4V Role of Small Cracks, International Journal of Fatigue, No 24, p. 1047-1062, (2002).

[8] Newman, J., C.and Haines, M., J., Verification of Stress-Intensity Factors for Various Middle-Crack Tension Test Specimens, Engineering Fracture Mechanics, No 72, p. 1113-1118, (2005).

[9] Fatemi, A., Plaseied, A., Khosrovaneh, A., K., Tanner, D., Application of Bilinear Log-Log Model to Strain Controlled Fatigue Data of Aluminum Alloys and Its Effect of Life Predictions, Int. Journal of Fatigue, No 27, p. 1040-1050, (2005).

[10] Moiser B., Weber, L., Mortensen, A., Damage Accumulation During Cycling Loading of a Continuous Alumina Fibre Reinforced Aluminum Composite, Scripta Materialia, No 53, p. 1111-1115, (2005).

[11] Wang, Q., Y., Kawagoishi, N., Chen Q., Fatigue and Fracture Behavior of Structural Al-Alloys up to very Long Life Regimes, Int. J. Fatigue, No 28, $\mathrm{p}$ 1572-1576, (2006)

[12] Borrego, L.,P., Costa, J., M., Ferreira, J., M., Fatigue Crack Growth in Thin Aluminum Sheets under Loading Sequences with Periodic overloads, ThinWalled Structures, No 43, p. 772-788, (2005).

[13] Jeong, D., Y., Mixed Mode Fatigue Crack Growth in Test Coupons Made from 2024-T3 aluminum, Theorical and Applied Fracture Mechanics, No 42, p. 35-42, (2004).

[14] Avci A., Arikan H., Akdemir A., , Fracture Behavior of Glass Fiber Reinforced Polymer Composite, Cement and Concrete Research, No 34, pp 429-434, (2004).

[15] Erkendirci Ö., Avci A., Akdemir A., Fatigue and Fracture Behavior of Woven Steel Reinforced Polyethylene Composites, J. Reinforced Plastics, Vol. 00 No. 00, March 2008

[16] ASTM E 647, The Middle Tension Specimens, pp 616-619, (2000).

[17] Beaumont W. R., Schults M., Friedrich K., Failure Analysis of Composite Materials, Technomic Publishing Co, (1990).

[18] Friedrich K., "Application of Fracture Mechanics to Composite Materials", Elsevier Science Publishers B. V. (1989). 
Table1. Tensile properties of the composite material

\begin{tabular}{ll}
\hline Property & \multicolumn{1}{c}{ Value } \\
\hline $\mathrm{E}_{1}$ & $76000 \mathrm{MPa}$ \\
$\mathrm{E}_{2}$ & $47000 \mathrm{MPa}$ \\
$v_{12}$ & 0.54 \\
Yield Strength $\left(\sigma_{Y S}\right)$ & $62 \mathrm{MPa}$ \\
Max. Strength $\left(\sigma_{u}\right)$ & $84 \mathrm{MPa}$ \\
\hline
\end{tabular}

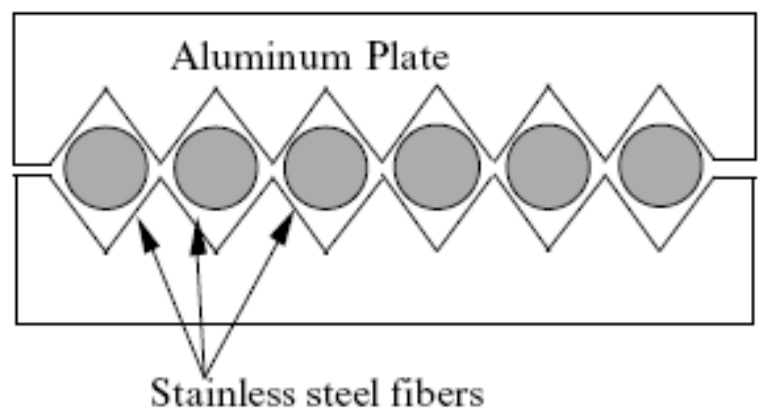

Fig. 1. Production of laminated composite.
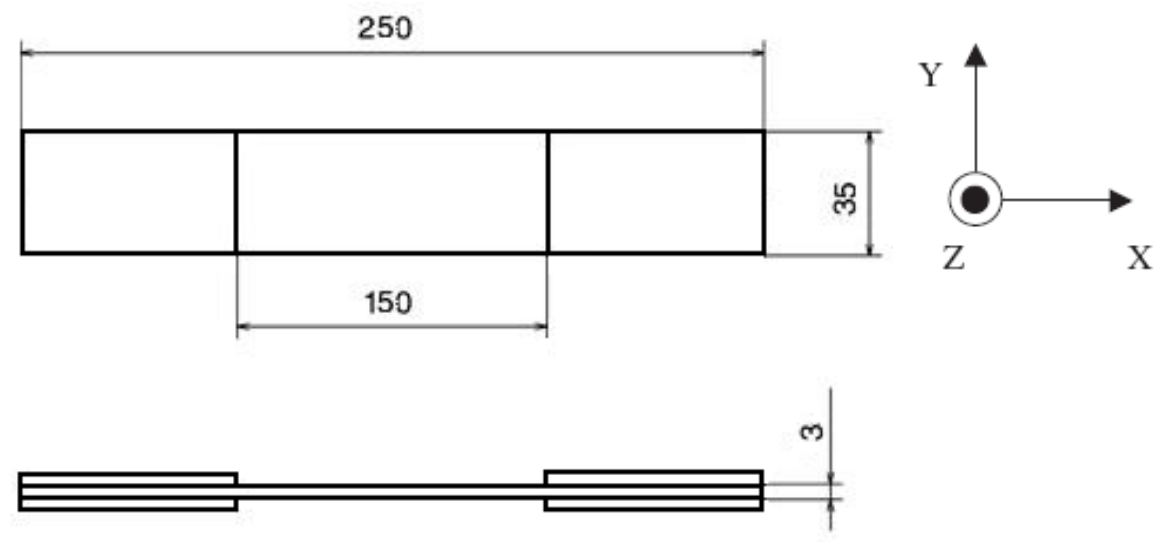

Fig. 2. Test specimen for the tensile test. 


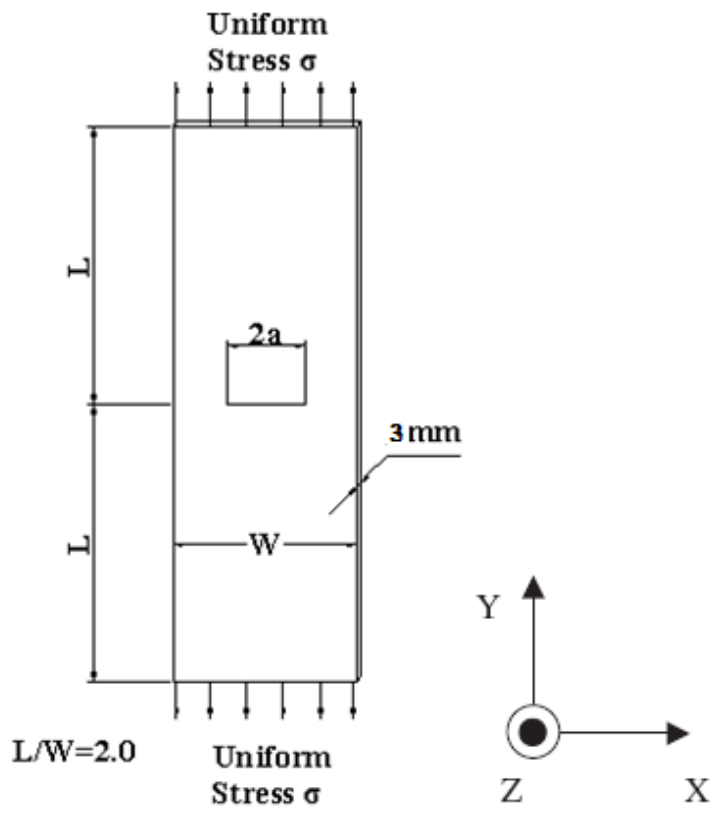

Fig. 3. $M(T)$ test specimen with through thickness crack for the fatigue tests according to ASTM E-647.

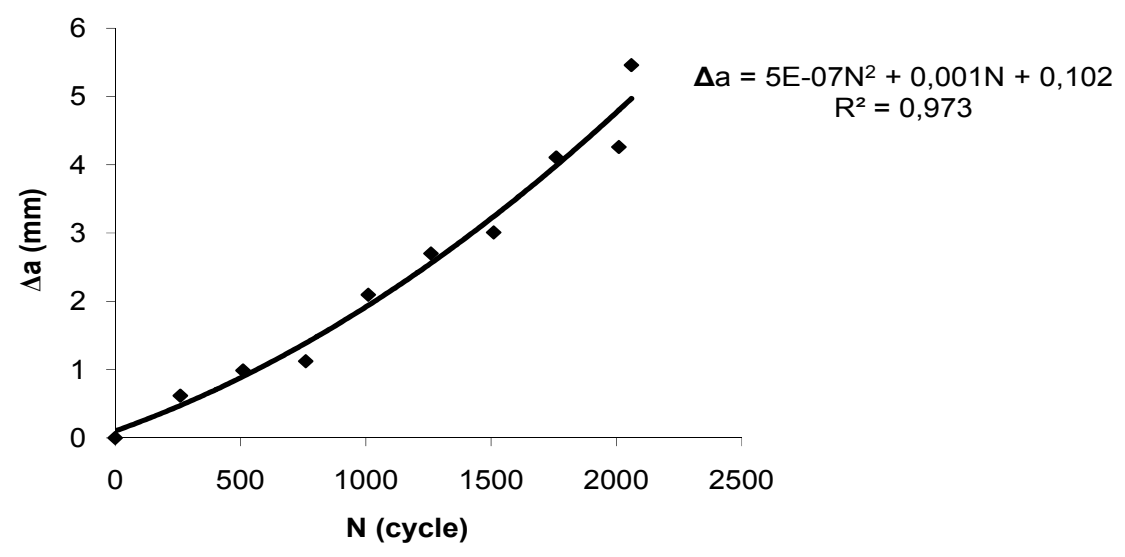

Fig. 4. The variation of crack length (a) with cycle $(\mathrm{N})$ at $0^{\circ}$ cracked fatigue specimen 


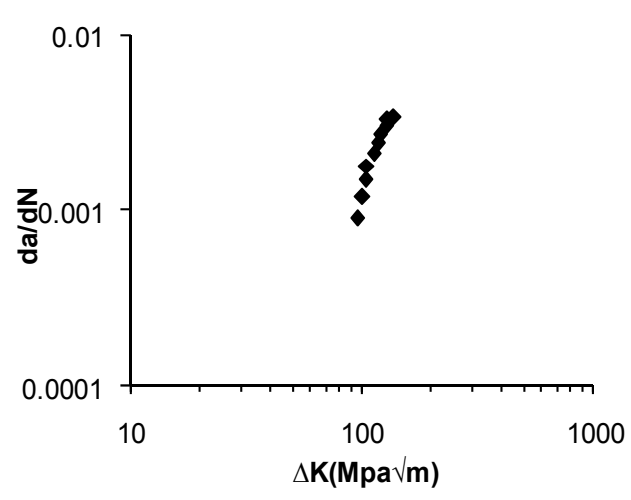

Fig. 5. Fatigue crack propagation behavior of composite material (da/dN- $\Delta \mathrm{K}$ curve).

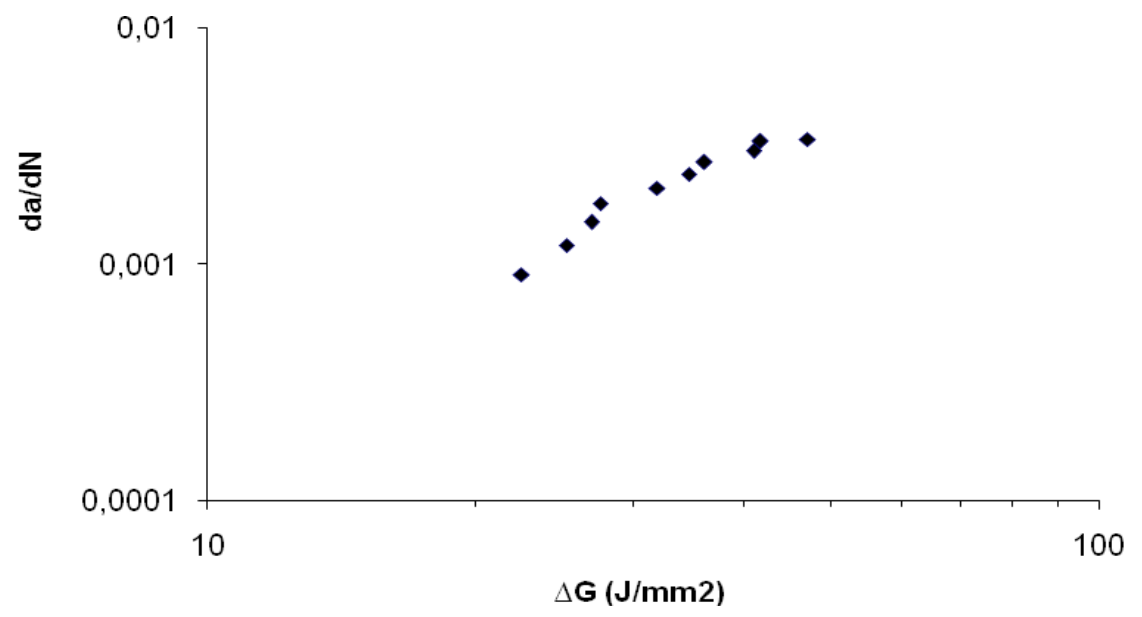

Fig. 6. The relationship between the crack growth rate da/dN and the strain energy release rate, $\Delta \mathrm{G}$.

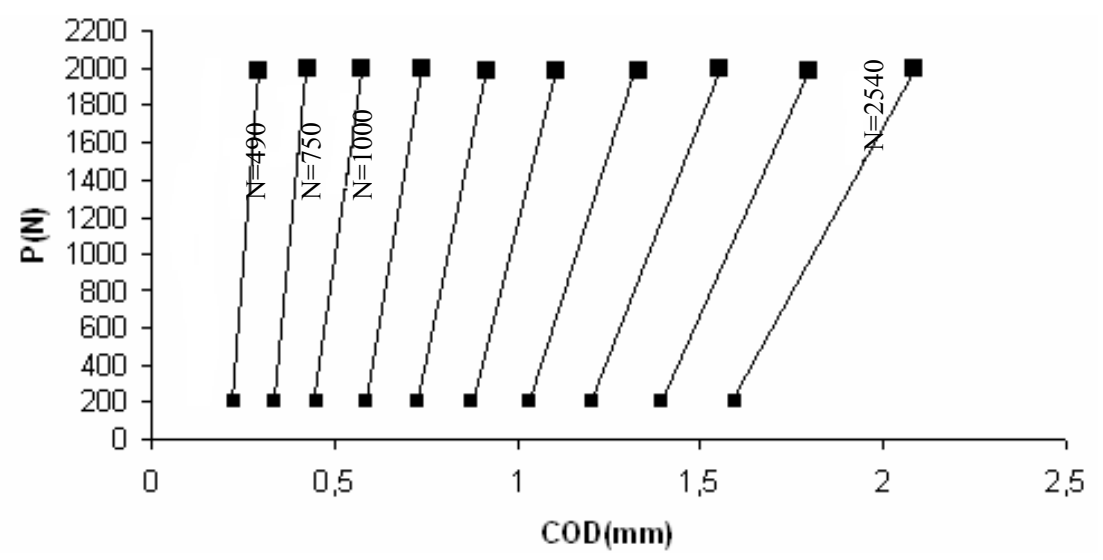

Fig. 7. The load-COD curve of composite material. 


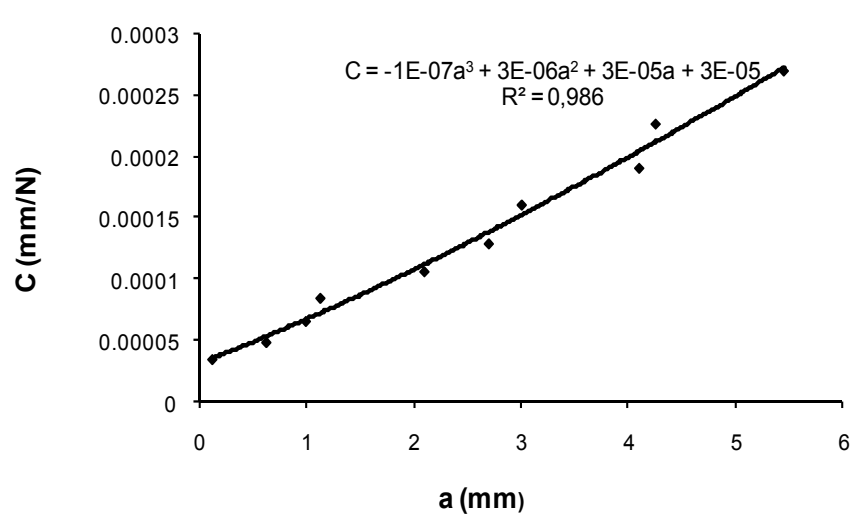

Fig. 8. Compliance - crack growth (C/a) curve of composite material.

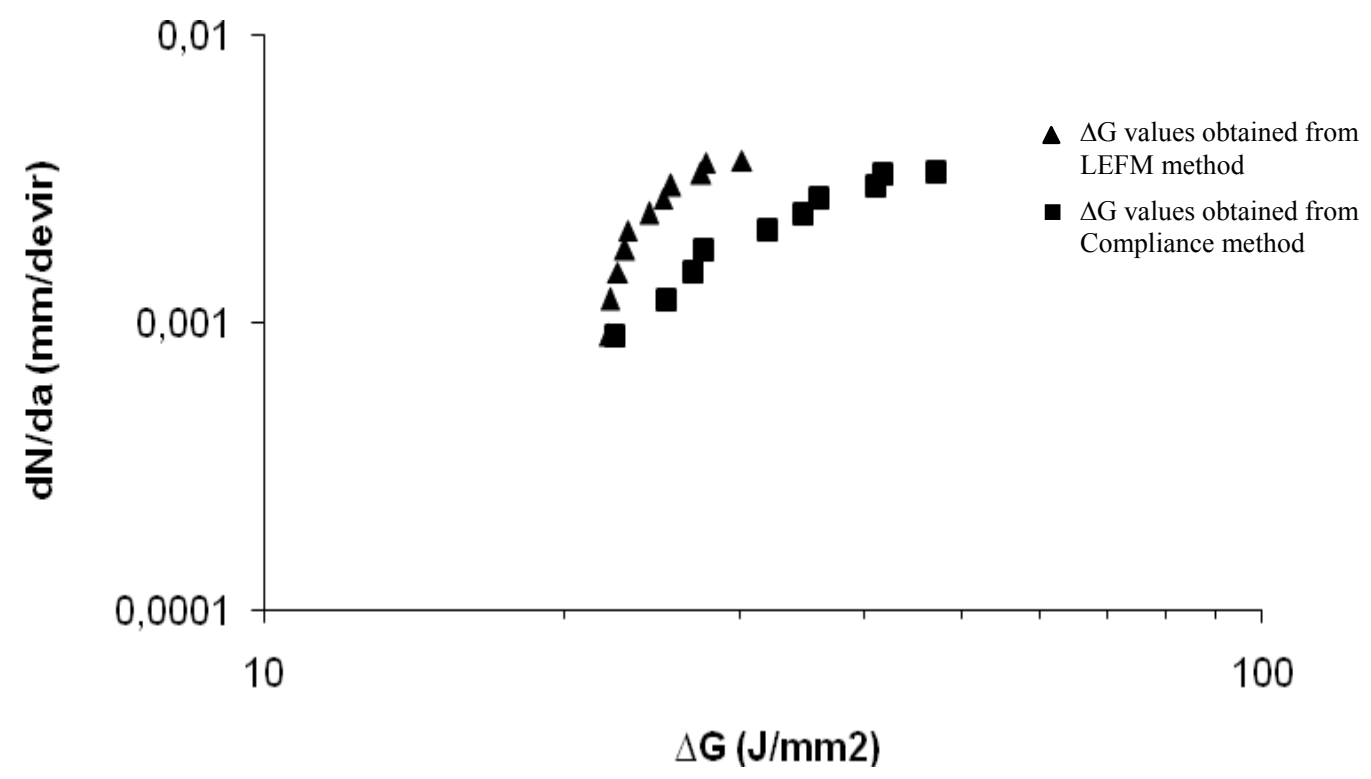

Fig. 9. da/dN- $\Delta \mathrm{G}$ curves of composite material with $0^{\circ} \mathrm{crack}$ angle.

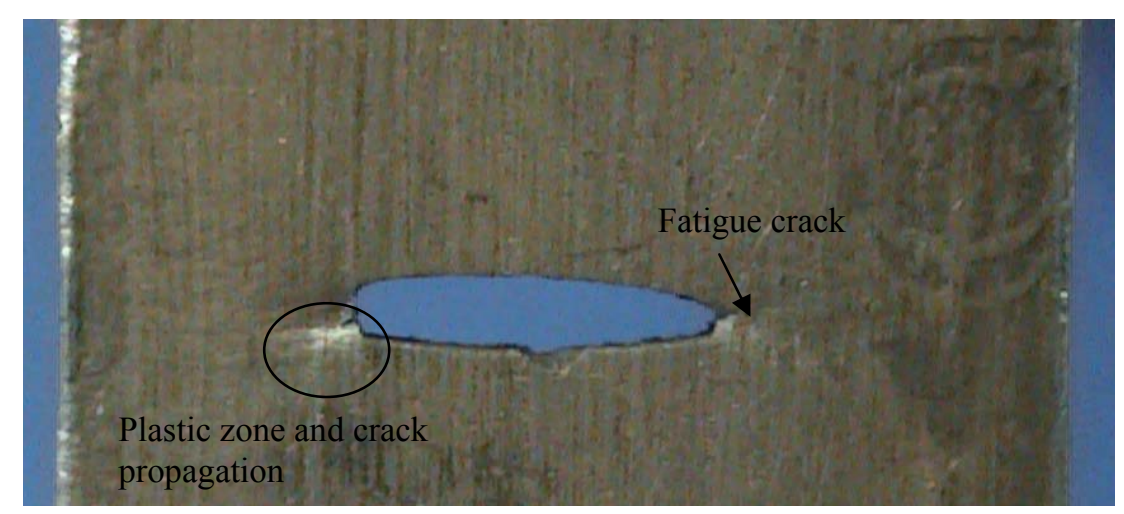

Fig. 10. Fatigue crack growth of the specimen 


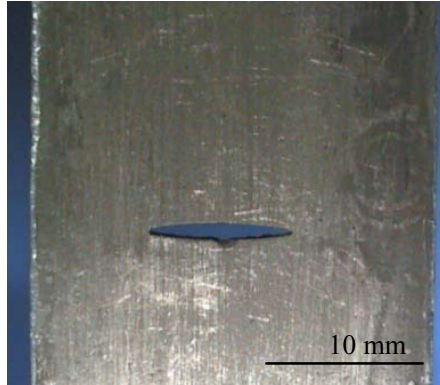

(a)

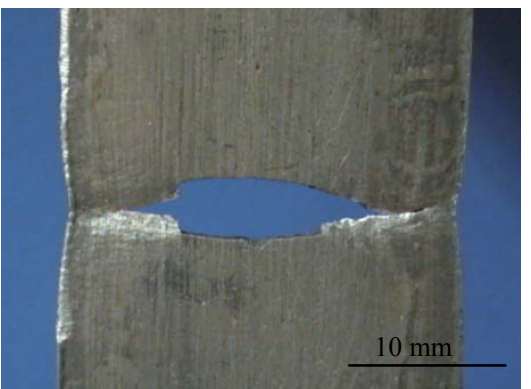

(b)

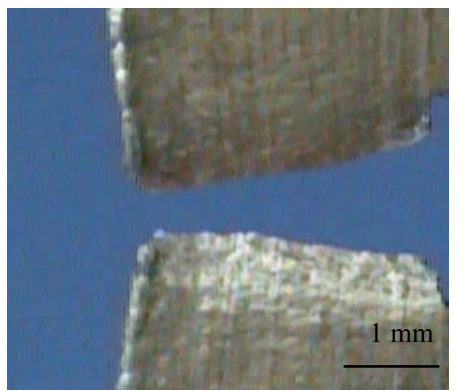

(c)

Fig. 11. The initial state and fracture photos of fatigue specimen

(a-) the initial state of specimen with middle through thickness crack

(b-) the specimen after failure

(c-) the area crack progressed 